\title{
ANALYZING AND MODELING THE SPATIOTEMPORAL DYNAMICS OF URBAN EXPANSION: A CASE STUDY OF HANGZHOU CITY, CHINA
}

\author{
Jie ZHAO ${ }^{1}$, Wenfu YANG ${ }^{2,3}$, Junhuan $\mathrm{PENG}^{2}$, Cheng $\mathrm{LI}^{4}$, Zhen $\mathrm{LI}^{3}$, Xiaosong $\mathrm{LIU}^{3}$ \\ ${ }^{1}$ Belt \& Road Institute, Jiangsu Normal University, Xuzhou, China \\ ${ }^{2}$ School of Land Science and Technology, China University of Geosciences, Beijing, China \\ ${ }^{3}$ Shanxi Coal Geology Geophysical Surveying Exploration Institute, Jinzhong, China \\ ${ }^{4}$ School of Architecture \& Design, China University of Mining and Technology, Xuzhou, China
}

Received 24 April 2019; accepted 5 November 2019

\begin{abstract}
Understanding the spatiotemporal characteristics of urban expansion is increasingly important for assisting the decision making related to sustainable urban development. By integrating remote sensing (RS), spatial metrics, and the cellular automata (CA) model, this study explored the spatiotemporal dynamics of urban expansion and simulated future scenarios for Hangzhou City, China. The land cover maps (2002, 2008, and 2013) were derived from Landsat images. Moreover, the spatial metrics were applied to characterize the spatial pattern of urban land. The CA model was developed to simulate three scenarios (Business-As-Usual (BAU), Environmental Protection (EP), and Coordination Development (CD)) based on the various strategies. In addition, the scenarios were further evaluated and compared. The results indicated that Hangzhou City has experienced significant urban expansion, and the urban area has increased by $698.59 \mathrm{~km}^{2}$. Meanwhile, the spatial pattern of urban land has become more fragmented and complex. Hangzhou City will face unprecedented pressure on land use efficiency and coordination development if this historical trend continues. The CD scenario was regarded as the optimized scenario for achieving sustainable development. The findings revealed the spatiotemporal characteristics of urban expansion and provide a support for future urban development.
\end{abstract}

Keywords: urban expansion, spatiotemporal dynamics, remote sensing, spatial patterns, cellular automata model, future scenario.

\section{Introduction}

In recent decades, rapid urbanization has been accompanied by significant increases in urban populations (GarcíaNieto et al., 2018; Yang, Liu, Li, \& Du, 2018). The proportion of the urban population increased from $30 \%$ to $55 \%$ during the period of 1950-2018, and this proportion is projected to reach $68 \%$ by 2050 (United Nations, 2018). As the largest developing country in the world, China has experienced significant urbanization since the implementation of its reform and opening policy in 1978. Urbanization is the most powerful force that results in land use/ land cover (LULC) change around the world (Simwanda \& Murayama, 2018). With ongoing urbanization, lands comprising the natural resource base, such as forest, wetlands, and agriculture, have been converted to urban land (Son, C. F. Chen, C. R. Chen, Thanh, \& Vuong, 2017). Although urban land covers only a small proportion of the Earth's land surface, urban expansion has had significant impacts on climate change (H. Kim, Y. K. Kim, Song, \& Lee, 2016), hydrological cycles (Aladejana, Salami, \& Adetoro, 2018), and ecosystems (Zang et al., 2017). The urban population proportion in China is projected to reach $80 \%$ by 2050 , according to a United Nations report (United Nations, 2018). There is no doubt that continuous urban expansion has imposed enormous pressure on sustainable development. Given the importance of urban expansion and its long-term effects, it has become a crucial topic in integrated ecological and socioeconomic research (Li, Sun, \& Fang, 2018; Kaza, 2013). Thus, it is worth exploring the spatiotemporal dynamics of urban expansion, which can support urban planning and decision-making efforts related to sustainable urban development.

Quantifying the spatial and temporal patterns of urban expansion is an important prerequisite for understanding its impacts on ecological processes. To acquire a better understanding of urban expansion processes, recent issues related to urban expansion have been emphasized. A large

${ }^{*}$ Corresponding author. E-mail: cheng.li@cumt.edu.cn 
number of studies have been conducted to monitor and analyze the urban expansion process. Many studies have been devoted to revealing how urban expansion alters the spatial configuration of urban land patterns (Benza, Weeks, Stow, López-Carr, \& Clarke, 2016; Estoque \& Murayama, 2013). The integration of land cover maps and spatial metrics has been widely used to characterize various structural dimensions of land changes, such as size, distribution, shape, and arrangement (Liu \& Yang, 2015), allowing for the exploration of the urban expansion process and its impact. Herold, Couclelis, and Clarke (2005) applied remote sensing (RS) and spatial metrics to improve the analysis of urban expansion. Chakraborti, Das, Mondal, Shafizadeh-Moghadam, and Feng (2018) analyzed the urban dynamics using a selection of landscape metrics. By using spatial metrics, Wu, Jenerette, Buyantuyev, and Redman (2011) quantified the spatiotemporal patterns of urbanization. The spatial metrics were shown to be effective in examining the urban expansion pattern. Although there is considerable literature about the theory and application of spatial metrics, there is still a lack of understanding about how urban spatial patterns vary spatially at the local scale. Previous studies used the entire study area to quantify the urban spatial pattern. However, the effects of scale on spatial pattern analysis were ignored in many studies.

Effective spatial planning policy is important for achieving sustainable urban development, which can mitigate the negative effective of urban expansion. However, the lack of analysis of multiple future urban expansion scenarios could affect the effectiveness of spatial planning policies. Scenario-based urban simulations and related impact assessments can assist decision makers in evaluating the impacts of different strategies and provide support for urban sustainable development. Many urban spatial models have been developed to explain the urban expansion process and to predict future urban expansion (Fuglsang, Münier, \& Hansen, 2013; Zhang, Huang, He, Dan, \& Liu, 2019; Abo-El-Wafa, Yeshitela, \& Pauleit, 2018). However, most of these models still face the challenges of representing the complexity of an urban system. The cellular automata (CA) model is a powerful tool for reproducing and simulating the urban expansion process due to its simplicity, flexibility, and intuitiveness (Agyemang \& Silva, 2019; Tripathy \& Kumar, 2019). In addition, various future urban expansion scenarios were generated by modifying the parameters in the CA models, which can simulate the consequences of decisions that follow different development strategies. For instance, $\mathrm{Xu}, \mathrm{X}$. Zheng, and M. Zheng (2019) developed two scenarios (status quo scenario, urban planning development scenario) and used the CA model to analyze the spatiotemporal dynamics of Beijing, China. Fuglsang et al. (2013) simulated different future urban expansion scenarios (business as usual, growth within limits, new welfare) for the Copenhagen metropolitan area. By using the CA model, Carter (2018) developed a long descent scenario and an upward spiral scenario for exploring the relationship between future land cover scenarios and adaptive capacities to climate change. More effective decisions can be obtained in urban development strategy by understanding the environmental impacts under different scenarios. Although the CA model is effectively applied in urban studies, there are still existing gaps between decision-making process and CA models. Urban models suffer from the lack of existing quantitative evaluations of urban expansion scenarios.

The studies of urban urban expansion in China have focused on the first-tier cities, such as Beijing and Shanghai (Yang et al., 2018; Song, Pijanowski, \& Tayyebi, 2015; Tian, Li, Yan, \& Wang, 2017). The urban expansion in second-tier cities has not gained enough attention. We selected Hangzhou, the capital of Zhejiang Province, as the case, because of its representativeness of similar large cities in China, especially provincial capitals. Unlike Beijing, Tianjin, Shanghai, and Chongqing, cities that are directly administered by the central government, Hangzhou and other provincial capitals are under the control of their respective provincial governments. By considering these different characteristics of provincial capitals from firsttier cities, an empirical study of Hangzhou will enrich our understanding of urban expansion in large Chinese cities, bringing insight into the possible solutions to urban expansion.

Taking Hangzhou City as the case study, this study aims to explore the urban expansion process in the study area to better understand them and provide support for urban planning and decision making related to sustainable urban development. The specific objectives are to (1) extract the historical land cover information for Hangzhou City by interpreting remote sensing images; (2) examine the spatiotemporal dynamics of urban land patterns at global and local scales; (3) simulate the multiple future urban expansion scenarios by incorporating various parameters in the CA model; and (4) analyze the urban expansion scenarios.

\section{Materials and methods}

\subsection{Study area}

This study was conducted using Hangzhou City, China, as the case study. Hangzhou City $\left(29^{\circ} 11^{\prime} \mathrm{N}-30^{\circ} 33^{\prime} \mathrm{N}\right.$, $118^{\circ} 21^{\prime} \mathrm{E}-120^{\circ} 30^{\prime} \mathrm{E}$ ) is located in the southern part of the Yangtze River Delta (Figure 1). It is one of the most rapidly expanding areas in China. Hangzhou City has a total administrative area of approximately $3358 \mathrm{~km}^{2}$. The city has a northern-monsoon-influenced humid subtropical climate, with an average annual temperature of $16.5^{\circ} \mathrm{C}$. The annual precipitation is $1454 \mathrm{~mm}$. The Qiantang River is the major river in this area. Hangzhou is composed of eight municipal districts, including Gongshu, Shangcheng, Xiacheng, Jianggan, Yuhang, Xihu, Xiaoshan, and Binjiang. The major land cover types in Hangzhou City include built-up land, crop land, vegetation, and water body. As the capital city of Zhejiang Province, Hangzhou is well 
known as one of the most rapidly expanding cities in China. Its gross domestic product (GDP) increased from 178 billion RMB in 2002 to 1255.6 billion RMB in 2017, which ranked 10th relative to other cities in China. By the end of 2017, the total population in Hangzhou was approximately 9.46 million (the urban population was 7.27 million, accounting for $76.8 \%$ of the total population). During the rapid urbanization process, a series of environmental and ecological problems have emerged, and they threaten sustainable development. These problems include the conflict between the supply of land and the increasing demand for land, the significant change in spatial patterns, and the low efficiency of conservation. The development characteristics and the sustainable problems related to the rapid urbanization in Hangzhou City are representative of economically developed cities in developing countries. Considering the representative condition, the case study of Hangzhou City can contribute to provide a better understanding of the urban expansion process.

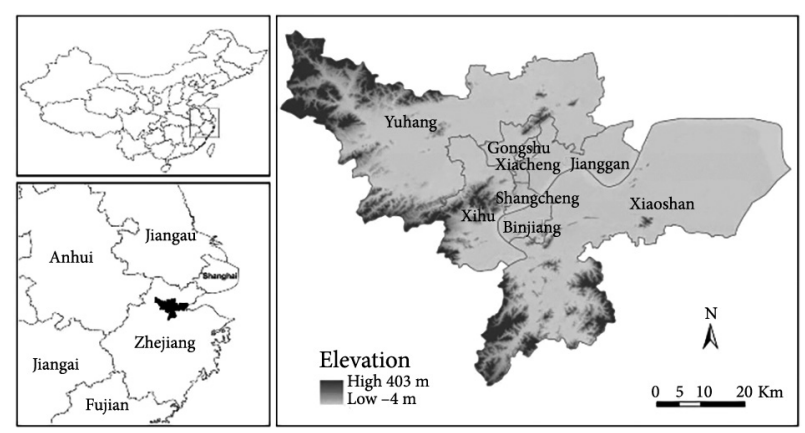

Figure 1. Location of study area (Hangzhou) and its topography

\subsection{Data}

In this study, various data were collected. The cloud-free Landsat 5 TM images from 2002 and 2008 and the Landsat 8 OLI image from 2013 were the main data sources used to obtain land cover information in Hangzhou City, and these data were acquired from the U.S. Geological Survey (USGS). After geometric correction, the remote sensing images were classified into four land cover categories by using the maximum likelihood classifier (MLC). The overall classification accuracy calculated for 2002, 2008, and 2013 was $88 \%, 92 \%$, and 90\%, respectively. In addition, potential variables representing the natural and socioeconomic factors were collected in this study, which included a digital elevation model (DEM), road maps, population data, and a master plan for 2030. All the spatial data were projected to the Universal Transverse Mercator coordinate system and sampled to the cell size of $100 \mathrm{~m}$.

\subsection{Analysis of spatial pattern}

To further analyze the spatiotemporal dynamics of urban expansion, gradient analysis was conducted by creating multiple buffers with 1-km distance intervals and a maximum distance of $20 \mathrm{~km}$ to the city center. For each buffer region, the area of newly developed land was statistically obtained.

In addition, a set of spatial metrics were calculated to quantify the urban spatial pattern using Fragstats 4 (McGarigal, Cushman, \& Ene, 2012). Four class-level spatial metrics in Fragstats were chosen to quantify the composition and configuration features of urban land. Different spatial metrics offer different information related to urban expansion patterns. The total area (TA) measures the increase in the total urban area. The number of patches (NP) describes the number of each type of urban land subdivision. The NP increases when new urban patches are developed. The largest patch index (LPI) indicates the percentage of the largest urban patch. The LPI equals 100 if the urban land is composed of a single urban patch, and the LPI increases as urban areas become more integrated and aggregated with urban cores (Dadashpoor, Azizi, \& Moghadasi, 2019). The mean Euclidean nearest-neighbor distance (ENN_MN) was calculated to characterize the dispersion of urban land patterns. SHAPE_MN was used to quantify the how compact each urban patch was. As the value of SHAPE_MN increases, the urban patches become less compact.

Both the entire study area and the block levels were applied in this study, which aimed to discover the urban expansion pattern at different spatial scales. The selected spatial metrics were first calculated for the entire study area to quantify the spatial patterns. In addition, the spatial metrics were further calculated for each block to localize the changes in the urban spatial patterns. Before calculating the spatial metrics at the block scale, a test was conducted using the block sizes of $1 \mathrm{~km}, 2 \mathrm{~km}$ and $3 \mathrm{~km}$ to identify the size to be used in this study. The block size of $2 \mathrm{~km}$ was selected, as it retained more detailed information than did the larger block size. Moreover, when the block size of $1 \mathrm{~km}$ was used, either no urban patch or only a few urban patches could be found in some blocks. This condition could produce noise in spatial pattern analysis. Therefore, the land cover maps were split into several sampling blocks with the size of $2 \mathrm{~km}$. The selected spatial metrics were calculated for each block using Fragstats 4.2 to quantify the spatiotemporal patterns of urban land.

\subsection{Development of cellular automata model}

The CA model was further developed to provide more information on urban expansion as well as to support decision making related to sustainable development in terms of scenario simulation. To obtain a realistic expression of the complex urban system, the CA model was quantitatively and spatially controlled by transition rules (Aburas, Ho, Ramli, \& Ash'aari, 2016). The state of a cell at time $t+1$ is determined as a function of the state of the cell at time $t$ and the transition rules of the CA model (White \& Engelen, 2000). The transition rule can be further established according to the potential transition values of the cells within the study area, which determine the probability that the non-urban cells will be converted to urban cells. The potential transition value $P_{i j}$ for cell $(i, j)$ can be 
calculated using a combination of urban expansion factors:

$$
P_{i j}=S_{i j} \times N_{i j} \times C O N S_{i j} \times V_{i j},
$$

where $S_{i j}$ indicates the suitability value for the non-urban land conversion at time $t$. It is formulated in a logistic form as follows:

$$
S_{i j}=\frac{\exp (z)}{(1+\exp (z))},
$$

where $z$ indicates the score of the urban expansion factors of cell $(i, j)$ :

$$
z=b_{0}+\sum_{n} b_{k} \times s f_{k, n o r},
$$

where $b_{0}$ is the intercept; and $s f_{k, n o r}$ indicates the normalized value of the suitablity factor $k$, which potentially affect the conversion from non-urban land to urban land. A set of suitability factors that contribute to the conversion from non-urban land to urban land are involved in the CA model, and these factors include slope, proximity to a major road (Pro2MajR), proximity to a minor road (Pro2MinR), proximity to a city center (Pro2Cen), and population density (PopDen). The influence of the socioeconomic conditions in the region can be best characterized by the access that a location has to socioeconomic center, which has a significant effect on urban growth pattern. In this study, socioeconomic center can be represented by city center. Transportation plays an indispensable part in urban growth because a good transportation increases the accessibility of land and decreases the cost of construction. Different types of roads have varied strengths of impact or potential to attract new development. In this study, major roads and minor roads were considered. Population is the main driver of urban growth. The growth of urban population create urban land demand. More urban land will be required to satisfy further growth of urban population in the future. Slope is a main natural constraint, which has a negative effect on urban growth. $b_{k}$ represents the corresponding weight of each factor, which can be derived using the logistic regression model. Before the logistic regression model is conducted, all variables involved in Eq. (3) were normalized into the range of $0-1$ to avoid effects from using different measurement scales (Tian, Ouyang, Quan, \& Wu, 2011). The normalized value $s f_{k, n o r}$ for the suitability factor $k$ is calculated as follows:

$$
s f_{k, \text { nor }}=\frac{s f_{k}-\min \left(s f_{k}\right)}{\max \left(s f_{k}\right)-\min \left(s f_{k}\right)},
$$

where $s f_{k}$ is the suitability factor involved in the urban expansion process. Additionally, $\max \left(s f_{k}\right)$ and $\min \left(s f_{k}\right)$ represent the maximum and minimum values of the suitability factor $k$, respectively.

The suitability value $S_{i j}$ only considers the effects of static physical factors on urban expansion. Realistic urban expansion is also subjected to the influences of the dynamic factors, which are represented by the neighborhood effect. This method was used in previous studies to address the influences of spatial interactions on urban expansion. The neighborhood effect $N_{i j}$ within a $5 \times 5$ Moore neighborhood was assessed using the following equation:

$$
N_{i j}=\frac{\sum_{5^{2}-1} \operatorname{cond}\left(s t_{i j}=u r b a n\right)}{5^{2}-1},
$$

where $\operatorname{cond}\left(s t_{i j}=\right.$ urban $)$ is assigned 1 if the state of a cell within the neighborhood is urban land; otherwise, $\operatorname{cond}\left(s_{i j}=\right.$ urban $)$ is assigned $0 . N_{i j}$ equals 1 if the states of all cells within the neighborhood of cell $(i, j)$ are urban land.

Furthermore, urban expansion is also strongly limited by some natural constraints. For example, the conversion from non-urban to urban land is not allowed in a water body. The constraint value $\mathrm{CONS}_{i j}$ can be calculated using Eq. (6):

$$
\operatorname{CONS}_{i j}=\prod_{f=1}^{k} \operatorname{con}_{i j, f},
$$

where $\operatorname{con}_{i j, f}$ is the binary value of the constraint factor $f$ for the cell $(i, j) \cdot \operatorname{con}_{i j, f}$ returns 1 if cell $(i, j)$ is suitable for conversion to urban land. Otherwise, $\operatorname{con}_{i j, f}$ returns 0. $\mathrm{CONS}_{i j}$ is the product of some binary variables representing the constraints to urban expansion, and the cell cannot be converted to urban land when $C O N S_{i j}=0$.

By considering the complexity of the urban system, the simulation of urban expansion is subject to a high degree of uncertainty (He, Li, Zhang, Liu, \& Zhang, 2017). To achieve a realistic simulation of the urban system, a stochastic disturbance parameter is included in the CA model to represent the uncertainty factors affecting the actual urban expansion process.

$$
V_{i j}=1+(-\ln (\text { rand }))^{\alpha},
$$

where $V_{i j}$ is the stochastic disturbance parameter, rand represents the random values ranging from 0 to 1 , and $\alpha$ is the variable that could identify the degree of stochasticity. Moreover, $\alpha$ is assigned a higher value if a higher degree of stochasticity is involved.

Once the transition potential value of cell $(i, j)$ is derived, the transition rule of the CA model can be applied to identify which cells are converted to urban land and which cells remain unchanged. The non-urban cells will be selected to convert to urban land based on the transition potential value. The CA model selects the cells with the highest $P_{i j}$ to be transformed during each iteration. Meanwhile, the non-urban cells with lower values will remain static. Another iteration will begin, and the process will be repeated until the total urban land demand is satisfied.

It is important to conduct calibration and validation for the CA model because the performance of the CA model is strongly dependent on the accuracy of the transition rule, which involves various parameters that must 
be calibrated (Santé, Marcía, Miranda, \& Crecente, 2010; Newland, Maier, Zecchin, Newman, \& van Delden, 2018). It is necessary to calibrate the CA model using the historical urban expansion data before applying the CA model to simulate the future urban expansion scenario. In this study, the weights of the suitability factors in Eq. (3) and the random variables must be identified. Various methods have been proposed to calibrate the CA model, such as logistic regression and trial and error. In this study, an integrated method of logistic regression and trial and error was applied to estimate the parameters of the CA model. The basic idea of the integrated calibration method was to identify the optimal combinations of parameters that could produce a more realistic representation of the urban expansion process. Logistic regression was used to estimate the weights of the suitability factors, and the trialand-error method was applied to identify the random variables.

Validation was implemented by measuring the agreement between the simulated land cover maps and the observed maps. The quality of the CA model was evaluated from two aspects: cell-by-cell similarity and pattern agreement. The cell-by-cell similarity was assessed using an indicator called the "figure of merit" (FOM) (Pontius et al., 2008), which can be calculated using the following equation:

$$
F O M=\frac{B}{A+B+C} \times 100 \%,
$$

where $A$ represents the area of agreement due to area that was observed as developed and also simulated as developed. $B$ indicates the area of error where observed urban land was simulated as non-urban land. $C$ is the area of error where the observed non-urban land was simulated as urban land.

The spatial pattern similarity was also considered in the validation of the CA model by measuring the relative differences of the spatial metrics (NP, LPI, SHAPE_MN, ENN_MN) between the observed urban land and the simulated values. The relative difference $R d$ is calculated as follows:

$$
R d=\frac{1}{4} \times \sum_{i} \frac{L M_{s, n}-L M_{o, n}}{L M_{o, n}} \times 100 \%,
$$

where $L M_{s, n}$ and $L M_{o, n}$ are the value of the $n$th spatial metrics of the simulated and observed urban land, respectively. The $R d$ value decreases when the simulated spatial pattern is more similar to the observed spatial pattern.

\subsection{Simulation of future scenarios}

In addition to simulating the historical urban expansion process, the calibrated CA model was further applied to develop various urban expansion scenarios for Hangzhou in 2030. The simulation of alternative urban development scenarios can be used to assess the potential impact of urban expansion on the environment as well as to provide support for urban and regional planning. In this study, three urban expansion scenarios were designed for Hangzhou City. The land demand in 2030 was obtained from the urban master plan for Hangzhou.

The business-as-usual (BAU) scenario strictly follows the historical trend of urban expansion without any limitations or alterations. To consider the impact of rapid urban expansion on the environment, we designed the environmental protection (EP) scenario, which emphasized the protection of the environment and avoided environmental problems caused by urban expansion. Future urban expansion was limited by the environmental constraints. Like many cities in developing countries, Hangzhou City faces enormous challenges in terms of the environment and ecology. To solve a series of environment problems caused by the urban expansion process, urban expansion constraints were included in the CA model to prevent the environmental protection areas and forest areas from being urbanized. The constraints map was produced by using the land cover map from 2015 and a physical condition map that prevents forest land and environmental protection areas from being urbanized. Therefore, urban expansion is limited by the constraint area defined by the EP scenario.

The master plan of Hangzhou City for 2030 emphasizes balance among the urban development levels of the city core, the peri-urban area and the rural area. In addition, the Hangzhou government will make efforts to promote land use efficiency to address the conflict between the increasing land use demand for urban development and the limited land resources. Meanwhile, the demand for a better living environment also needs to be improved. To integrate this fact and the development strategy of Hangzhou City, the coordination development (CD) scenario was established, and this scenario coordinates the urban development in different areas and controls the urban expansion in the protection areas defined in the EP scenario.

Scenario analysis for Hangzhou City can provide a better understanding of the potential environmental and ecological consequences of urban expansion under various developmental strategies. This will lead to a better understanding of land use dynamics, driving forces for expansion patterns of built-up land, and planning policies among researchers, urban planners, and decision makers. Moreover, the results from this case study will have practical implications for the similar cities worldwide. Therefore scenario analysis can support decision making related to sustainable urban development (Xu, Haase, \& Pauleit, 2018). A set of spatial metrics (e.g., NP, LPI, SHAPE_MN, ENN_MN) were applied to evaluate the three scenarios by quantifying the spatial patterns of these scenarios at global and local scales. At the regional scale, the values of the spatial metrics provide a general description of the urban land pattern for the entire study area. To further reveal the spatial patterns of urban land at a smaller scale, the study area was divided into several square blocks. The selected spatial metrics were calculated for each block to locate the differences in the urban land patterns among the scenarios. 


\section{Results}

\subsection{Land cover dynamics}

Figure 2 illustrates the land cover data derived from the remote sensing images in 2002, 2008, and 2013, respectively. Hangzhou City has experienced significant land cover change during the period of 2002-2013. Continuous urban expansion was observed during the period of 2002-2013. Figure 2 shows the land cover dynamics in Hangzhou. As indicated in Table 1, the area of built-up land increased by $698.59 \mathrm{~km}^{2}$, from $305.63 \mathrm{~km}^{2}$ in 2002 to $1004.22 \mathrm{~km}^{2}$ in 2013 , or by $228.57 \%$ over the 11 years. It is noticeable that the annual growth rate of built-up land increased over two different periods, which suggests that Hangzhou City has witnessed significant urban expansion processes with an accelerating rate. In contrast, the crop land and forest land decreased by $26.95 \%$ and $14.94 \%$, respectively. The area of water bodies declined by $21.89 \%$.

A total of $698.59 \mathrm{~km}^{2}$ of land was converted to built-up land, which represents $20.8 \%$ of the total land. Most of the newly developed built-up land is from the transformation of crop land into built-up land. Over the 11-year period, built-up land increased by $624.41 \mathrm{~km}^{2}$ from the conversion of crop land, and this value represented $89.4 \%$ of the total new built-up land. Specifically, built-up land received
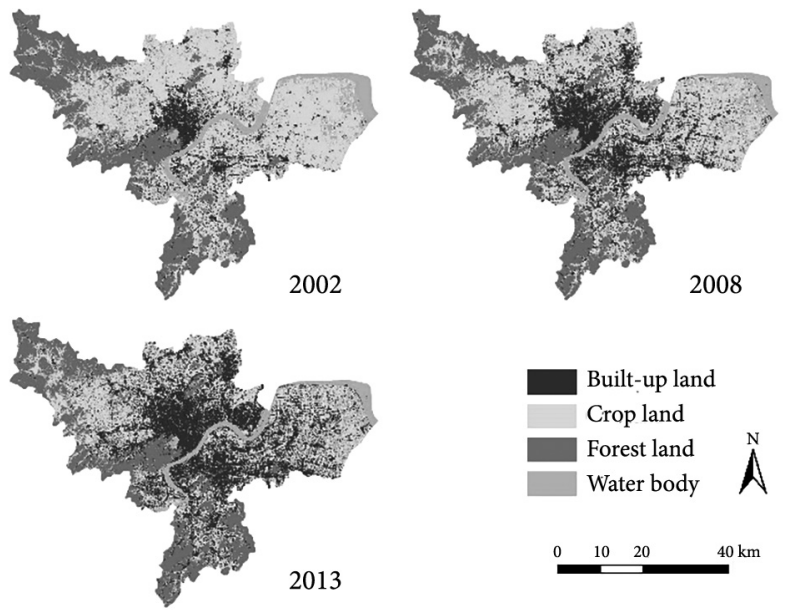

Figure 2. The land cover maps of Hangzhou City for 2002, 2008, and 2013

Table 1. The land cover statistical data for Hangzhou City. (Unit: $\mathrm{km}^{2}$ )

\begin{tabular}{|l|c|c|c|}
\hline & $\begin{array}{c}2002 \\
\text { (Percentage) }\end{array}$ & $\begin{array}{c}2008 \\
\text { (Percentage) }\end{array}$ & $\begin{array}{c}2013 \\
\text { (Percentage) }\end{array}$ \\
\hline $\begin{array}{l}\text { Built-up } \\
\text { land }\end{array}$ & $\begin{array}{c}305.63 \\
(9.10 \%)\end{array}$ & $\begin{array}{c}676.83 \\
(20.15 \%)\end{array}$ & $\begin{array}{c}1004.22 \\
(29.90 \%)\end{array}$ \\
\hline Crop land & 1792.04 & 1562.85 & 1309.01 \\
& $(53.35 \%)$ & $(46.53 \%)$ & $(38.97 \%)$ \\
\hline $\begin{array}{l}\text { Forest } \\
\text { land }\end{array}$ & 870.55 & 769.37 & 740.47 \\
\hline $\begin{array}{l}\text { Water } \\
\text { body }\end{array}$ & $35.92 \%)$ & $(22.91 \%)$ & $(22.05 \%)$ \\
\hline
\end{tabular}

$337.2 \mathrm{~km}^{2}$ and $302.8 \mathrm{~km}^{2}$ from crop land during the periods of 2002-2008 and 2008-2013, respectively. These results highlight the conflict between the limited land resources and the large demand for urban expansion.

The visual approach provides some general information on where urban expansion has occurred. Overall, the spatial pattern of urban land in Hangzhou represents some degree of dispersal and fragmentation. Urban development was found in both the city core and the peri-urban area. The study calculated the proportion of newly developed built-up land within $40 \mathrm{~km}$ of the city center during the period of 2002-2013. Within $40 \mathrm{~km}$ of the city center, the relationship between the distance and the increase in built-up land is plotted in Figure 3. For the two periods, the regions suffered more intensive urban expansion. In general, the buffer region with the distance of $40 \mathrm{~km}$ to the city center experienced remarkable urban expansion. Most of the newly developed built-up land was observed within a distance of 2-20 km to the city center, which implies that the urban expansion during this period was concentrated around the city core. The proportion of built-up land rapidly increased within the range of 6-12 km, which is where the peri-urban area with factories and sparse settlements was located. Furthermore, the intensity value decreased steadily in the range of $20-40 \mathrm{~km}$, which indicates urban expansion was rare in the rural area. During the period of 2002-2008, a significant increase in the built-up land growth intensity value was observed at the distance of $10-12 \mathrm{~km}$ to the city center. The urban growth intensity value decreased remarkably within the distance of 12-18 km. Compared to the previous periods, the peak value observed in the range of $10-12 \mathrm{~km}$ was lower during the period of 2008-2013. Moreover, the intensity value decreased slowly and steadily in areas $12-18 \mathrm{~km}$ from the city center. This result could be explained by the fact that further urban development in the city core becomes constrained due to the limited land resources still available. It is worth noting that the intensity value was larger than that in 2002-2008 beyond $26 \mathrm{~km}$, which suggests that the active area for high-intensity built-up growth expanded into the peri-urban areas and rural regions after the rapid urban expansion around the city core (Figure 3 ).

\subsection{Spatiotemporal patterns of urban expansion}

The evolution of urban land patterns during the study period was characterized by adopting the selected spatial metrics. The analysis of selected spatial metrics at the regional scale provided a general description of the urban spatial patterns. With accelerating urban expansion in Hangzhou City, the values of the spatial metrics indicated that the spatial patterns varied significantly. As shown from the calculation results (Table 2), the NP increased from 3678 to 4692 , indicating a significant increase in the degree of landscape fragmentation. The allocation of builtup land was composed of both the increased development of the historical city core, as indicated by the increase in the LPI, and the generation of new urban patches, as 


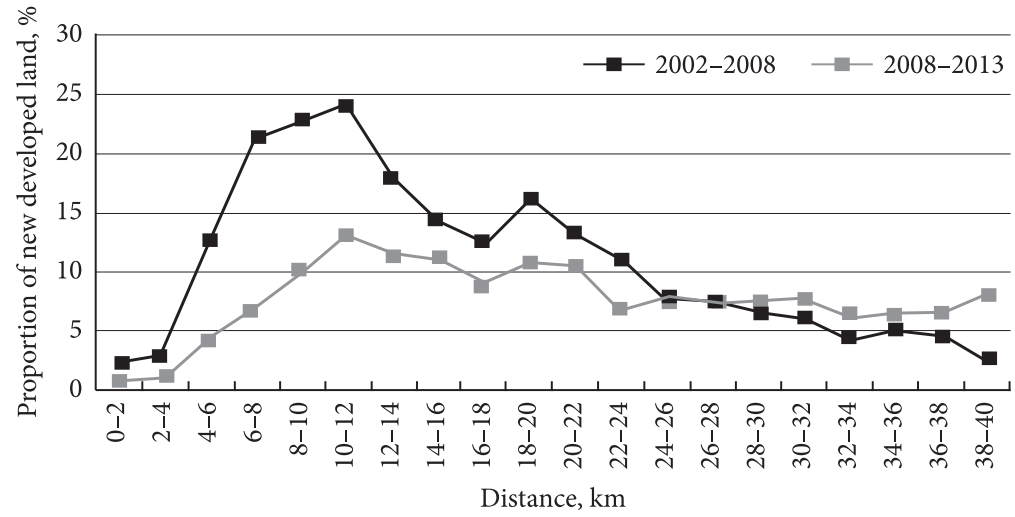

Figure 3. Change in the proportion of newly developed built-up land with distance to the city center

reflected by the increase in the NP. Over the study period, the decrease in the ENN_MN value suggests that the new urban development tended to infill around the existing urban patches. Additionally, the development of new urban patches, as indicated by the increase in the NP, also contributed to the decline of the ENN_MN. The continuous increase in the SHAPE_MN value reveals that an increasingly complex and irregular pattern emerged. Overall, the spatial pattern analysis represented Hangzhou's diffuse sprawling development.

Table 2. Statistical summary of spatial metrics calculated for Hangzhou City at the regional scale

\begin{tabular}{|l|c|c|c|}
\hline & 2002 & 2008 & 2013 \\
\hline TA & 30563 & 67683 & 100422 \\
\hline NP & 3678 & 4341 & 4692 \\
\hline LPI & 2.63 & 6.8 & 11.01 \\
\hline SHAPE_MN & 1.18 & 1.21 & 1.22 \\
\hline ENN_MN & 338.2 & 290.72 & 258.1 \\
\hline
\end{tabular}

To further reveal the spatial patterns at the local scale, the selected spatial metric values (e.g., TA, NP, LPI, and SHAPE_MN) were derived for each square block $(2 \times 2$ $\mathrm{km})$. As illustrated in Figure 4, the spatial pattern of urban land in each block experienced significant changes during the rapid urban expansion process, which was consistent with the changing trend of the spatial metrics analysis at the regional scale. More importantly, the spatial metrics analysis at the local scale revealed the spatiotemporal changes in the spatial pattern of urban land in response to urbanization. As explained by the change in TA, urban expansion was mainly concentrated in the city core in 2002. When comparing the results across different years, the area identified as experiencing significant urban expansion processes expanded to a larger area over time. The area with a large NP value transformed from the city core to the peri-urban and rural areas, which implied that new urban patches in the peri-urban and rural areas were more likely to be developed. Although urban expansion was still increasing, the intensity of the urban sprawl slowed after the rapid urban land development because the vacant land in the city core became exhausted and could no longer be converted to urban land. Most of the urban development was focused on the peri-urban and rural areas. The significant outlying pattern of development around the city core contributed to an increase in the NP value. In addition, the spatiotemporally varying SHAPE_MN value suggested that Hangzhou's urban land began to diffuse outward, which correlated with the change in TA. The urban land in the peri-urban areas presented more regular shapes and less isolated patterns. Additionally, the city core expanded to form larger and more complicated patches. Due to the massive construction of infrastructure and settlement in recent years, urban land became more dominant and irregular in shape over time. The spatial pattern analysis at both the global and local scales have provided a better understanding of the spatial pattern variation in response to urban expansion by revealing how urbanization spatiotemporally influenced the spatial pattern.
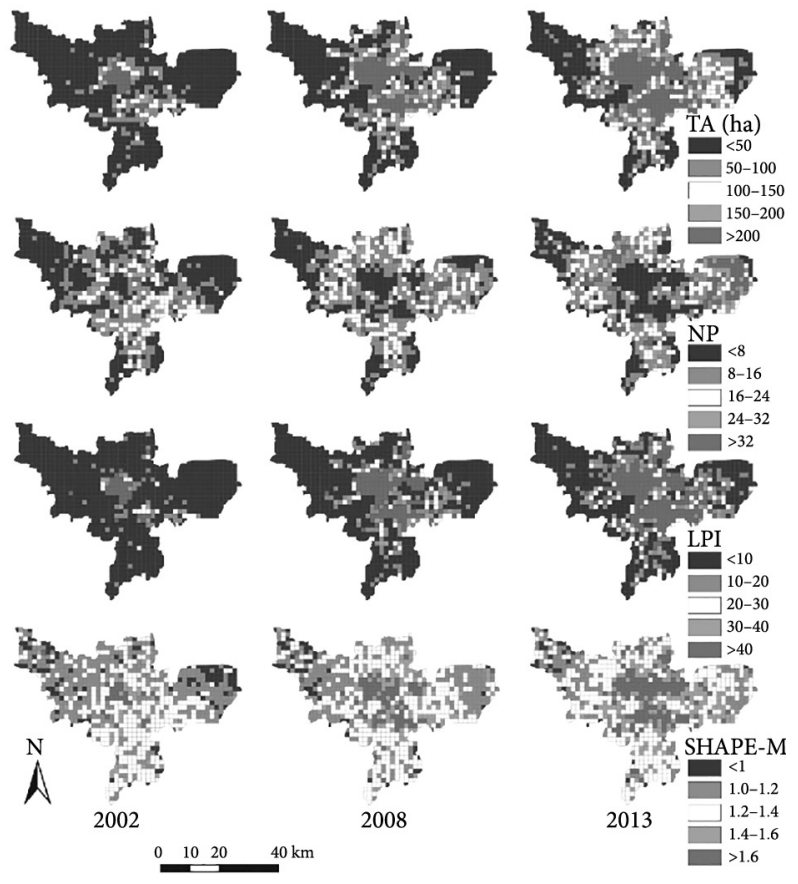

Figure 4 . The spatial metric values at the local scale 


\subsection{Development of urban expansion model}

The calibration of the CA model was conducted by applying logistic regression as well as trial-and-error methods. The weights of the suitability factors were identified using the logistic regression method. The random variable was estimated by adopting the trial-and-error method. The estimated parameters in the CA model are presented in Table 3.

Table 3. Calibrated parameters in the CA model.

\begin{tabular}{|l|c|c|}
\hline \multicolumn{1}{|c|}{ Parameter } & 2002-2008 & 2008-2013 \\
\hline Pro2Cen & -1.568 & -1.395 \\
\hline Pro2MajR & -1.473 & -1.631 \\
\hline Pro2MinR & -0.936 & -0.812 \\
\hline Slope & -1.727 & -1.063 \\
\hline PopDen & 0.709 & 0.348 \\
\hline Random Variable & 1.6 & 2.2 \\
\hline
\end{tabular}

The historical urban expansion process was simulated by using the CA model with the estimated parameters. Figure 5 shows the comparison between the observed urban land map and the simulated urban land map in 2008 and 2013, respectively. The FOM values indicate that there was $38.4 \%$ and $36.6 \%$ of overlap in the observed change and the simulated change in 2008 and 2013, respectively. The overall agreement between the observed urban land and the simulated urban land was represented by an overall accuracy of $90.2 \%$ and $90.9 \%$, respectively. The decreasing accuracy of the simulated results was observed, which highlighted the complexity of the urban expansion process. Accurately simulating urban development become more difficult when using the CA model because the influences of new urban development policy cannot be incorporated into the CA model.

In addition to assessing the simulation accuracy at the cell level, the similarity of spatial patterns between the simulated and observed urban land values was calculated
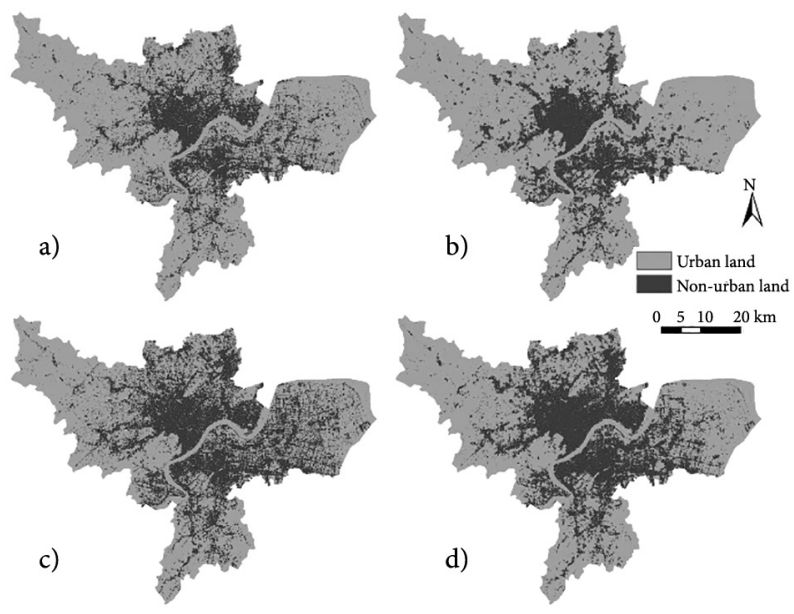

Figure 5. The comparison between the observed and simulated urban land cover patterns: a - observed 2008; b - simulated 2008; c - observed 2013; d - simulated 2013 to quantify the performance of the CA model at the pattern level. The selected spatial metrics were calculated to quantify the spatial pattern of urban land to estimate the similarity of urban spatial patterns between the simulated and observed urban land values. Table 4 presents the spatial metric values for the simulation results and the Rd value. The results suggested that the simulated urban land pattern was similar to the observed urban land pattern. However, the simulation results had relatively larger errors in the NP value. Fewer urban patches were produced when using the CA models.

Table 4. The spatial metrics of the observed and simulated urban land

\begin{tabular}{|l|l|c|c|c|c|}
\hline & & NP & LPI & $\begin{array}{c}\text { SHAPE } \\
\_M N\end{array}$ & $\begin{array}{c}\text { ENN } \\
\_M N\end{array}$ \\
\hline \multirow{3}{*}{2008} & Observed & 4341 & 6.7986 & 1.2051 & 290.7244 \\
\cline { 2 - 6 } & Simulated & 4125 & 6.9227 & 1.2343 & 300.3674 \\
\cline { 2 - 6 } & Rd(\%) & \multicolumn{5}{|c|}{3.13} \\
\hline \multirow{3}{*}{2013} & Observed & 4692 & 11.0132 & 1.2247 & 258.0981 \\
\cline { 2 - 6 } & Simulated & 4368 & 11.3573 & 1.2391 & 264.0730 \\
\cline { 2 - 6 } & Rd(\%) & \multicolumn{5}{|c}{3.38} \\
\hline
\end{tabular}

\subsection{Simulation of future urban expansion scenarios}

By using the calibrated CA model, the modeling configuration of the 2008-2013 period, and the input urban land map of 2013, three different urban expansion scenarios were simulated to predict the alternative spatial patterns of urban land in Hangzhou by the year 2030. Figure 6 presents the simulated urban expansion scenarios in 2030. Under the different scenarios, various spatial patterns of urban land were observed. The BAU scenario was simulated based on the assumption that the historical urban expansion trend would continue without any changes in development policy. The urban land expanded eastward and southward and created new development hotspots around the city center. In addition, a large amount of crop
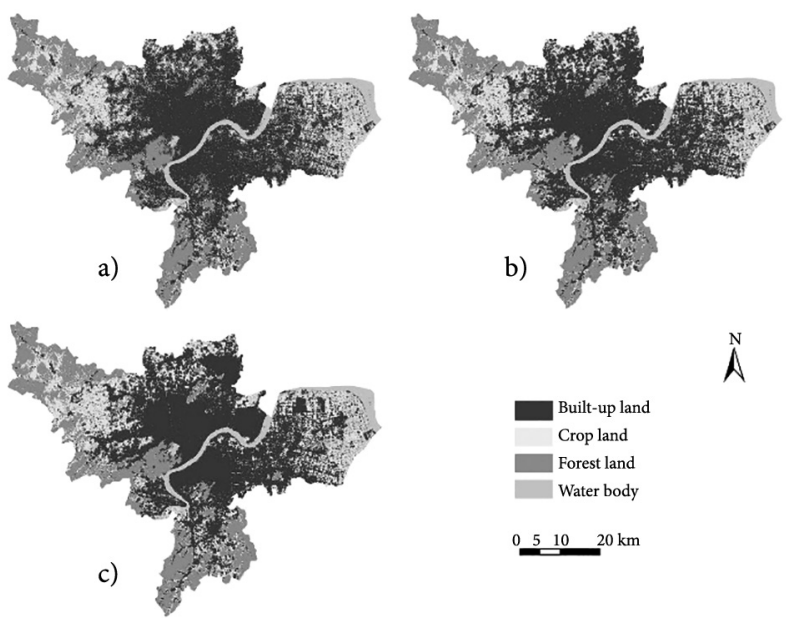

$\AA^{N}$

Figure 6. The simulated urban expansion scenarios: a - BAU scenario; b - EP scenario; c - CD scenario 
land in rural areas will be converted to built-up land by 2030. The expansion pattern also extends over environmental protection regions. However, the development of rural areas in the BAU scenario still retained a slow pace.

The EP scenario emphasizes the protection of environmentally sensitive regions. Therefore, some areas in the city center remained non-built over time due to these environmental constraints. A large part of the newly developed built-up land was far from the predefined environmentally sensitive regions.

Compared with the BAU and EP scenarios, different spatial patterns were observed under the CD scenario, which was characterized by compact polycentric development. Different from the concentrated development in the city core, the newly built-up land was more likely to be developed in several hotspots in the peri-urban and rural areas. Furthermore, the built-up land will become more compact by 2030. A regional balance in the spatial distribution of built-up land was observed in the CD scenario relative to the BAU and EP scenarios. Because of the inclusion of environmental constraints in the CA model, the urban expansion in protection areas was limited, which was similar to the results of the EP scenario.

To further clarify the differences between the three urban expansion scenarios, a set of spatial metrics were calculated at the global and local scales. As shown in Figure 7, the spatial metric values at the regional scale varied significantly, and the spatial pattern of each scenario was revealed. Moreover, the values of the spatial metrics at the local scale provide a better understanding of the differences among the three scenarios in terms of the urban expansion pattern (Figure 8). The characteristics of urban expansion under the three scenarios were discovered.

Compared to the urban land pattern in 2013, increases in the NP and LPI were observed in the BAU scenario, and these are presented in Figure 7. This change is attributed to the expansion of the city core and the generation

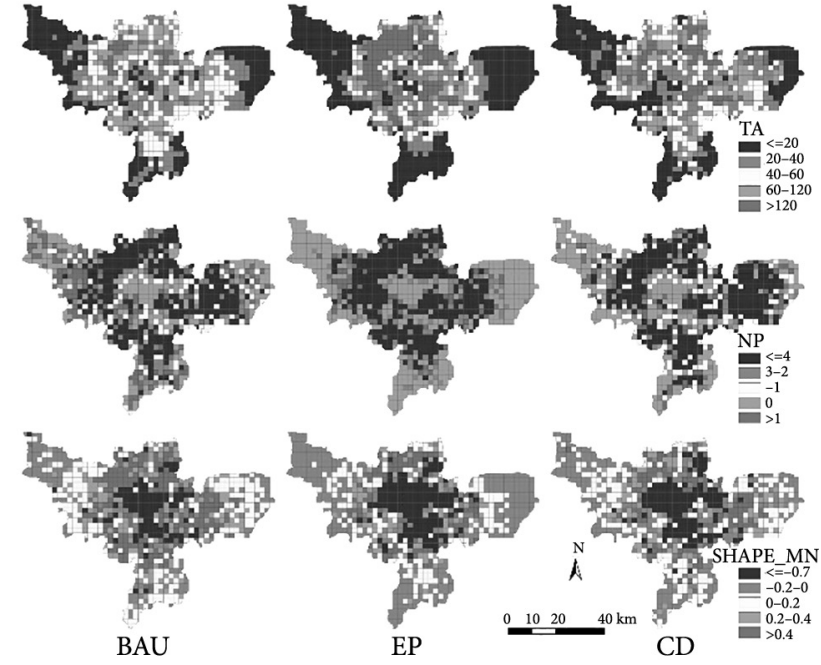

Figure 8. Comparison among the three scenarios and the observed urban spatial pattern of 2010 regarding the TA, NP, and SHAPE_MN values at the local scale

of new individual urban patches. As indicated by the decrease in ENN_MN, the non-urban land between the individual patches was further converted to urban land during the rapid urbanization process. The SHAPE_MN value is larger than those in the two other scenarios, which suggests that the urban land pattern will become more complicated. This is also demonstrated in Figure 8. According to the historical urban expansion trend, the rapid urban development around the city core will lead to an increase in the area of urban land. The rapid increases in SHAPE $\mathrm{MN}$ are concentrated in the peri-urban and rural areas. This result can be attributed to the fact that Hangzhou City will continue to diffuse outward. The urban expansion will result in larger and less irregular patches.

In contrast to the BAU scenario, the EP and CD scenarios have lower NP values in 2030. In addition, the peak

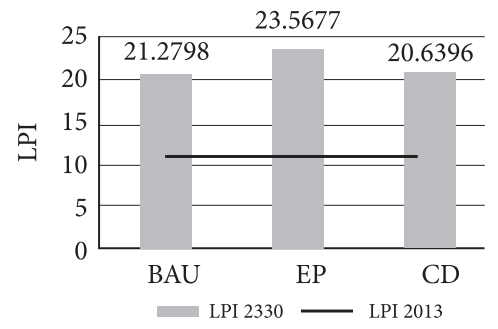

b)

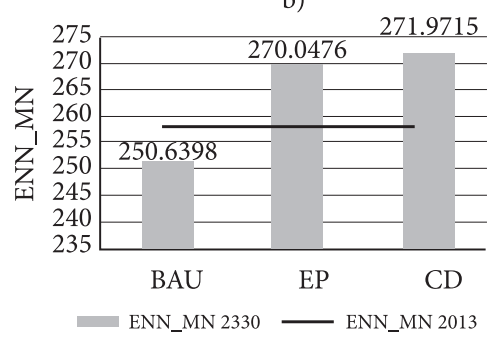

d)

Figure 7. Spatial metric values of urban land in the three scenarios and the observed urban land in 2013: a - NP value; $b$ - LPI value; $c$ - SHAPE_MN value; $d$ - ENN_MN value 
LPI value observed under the EP scenario indicates steady urban expansion in the city core. The abrupt drop in the SHAPE_MN value implies the urban land pattern will become more compact by reducing the generation of new urban patches and focusing on the development of infill. The new urban areas will be quickly assimilated into the existing city core. Most of the new urban development will be concentrated in the areas between the fragmented urban areas, where crop land will be converted into urban land to generate compact urban patches. The concentric urban pattern for development in Hangzhou will remain unchanged.

As shown in Figure 7, the CD scenario has the lowest NP, LPI, and SHAPE_MN values and the largest ENN_ $\mathrm{MN}$ value. The spatial characteristics of the urban areas of Hangzhou under the CD scenario will become increasingly compact by 2030, which is reflected by this scenario having the lowest SHAPE_MN value. Moreover, the lowest LPI value observed in 2030 indicates an increase in the area of new urban land beyond the existing city core, and this outcome is possibly due to the creation of new development hotspots in the peri-urban and rural areas. Although the developed urban patches will become more compact, outlying development occurred in the periurban and rural areas under the CD scenario. The allocation of new urban land is composed of the expansion of the historical city core as well as the establishment of new hotspots. However, the SHAPE_MN value is smallest among the three scenarios at the regional scale around the new developed hotspots. By 2030, the ENN_MN will increase in concert with the decrease in the NP value, implying that Hangzhou's urban areas will develop regularly. The polycentric compact urban land pattern of Hangzhou City will be shaped by 2030 . Under the CD scenario, the new urban area development occurs beyond the existing urban areas, which not only attracts residents to the periurban area but also promotes the long-term development potential of Hangzhou City.

\section{Discussion}

\subsection{Methodology implication}

To better understand the spatiotemporal dynamics of urban expansion and to optimize the future urban land allocation in Hangzhou City, this study proposed an analysis framework that integrated remote sensing, spatial metrics and the CA model. This study demonstrated that the proposed analysis framework could be appropriate and effective in terms of analyzing and simulating the complex urban expansion process.

The study agrees well with the previously reported effectiveness of the selected spatial metrics in terms of revealing the spatial patterns of urban land $(\mathrm{Li}, \mathrm{Zhao}, \& \mathrm{Xu}$, 2017; Vanderhaegen \& Canters, 2017). However, one of the major issues that has often been overlooked by previous studies is the scale effect of the spatial metrics on the pattern analysis. It is widely accepted that a variation in spatial scale could result in a change in the statistical analysis (Hayek et al., 2015). The spatial metrics at the regional scale provide only a general representation of the urban land patterns. This study differed in that we focused on the analysis of spatial patterns at both the regional and the local scales.

This study has attempted to demonstrate that the proposed CA model can be used as an effective tool to identify sustainable urban development policy under various urban expansion scenarios. By including the various development policies, the proposed CA model simulated three different scenarios (e.g., BAU, EP, and CD) for Hangzhou City in 2030. These scenarios may also help planners test the potential consequences of urban development policy. The calibration of the CA parameters has been shown to be a difficult task in CA modeling (Santé et al., 2010). The proposed calibration method (i.e., logistic regression model-trial and error) offers an appropriate way to identify the parameters in this study. Our study agrees well with the previously reported the usefulness of figure of merit and spatial metrics in the validation of CA model (García, Santé, Boullón, \& Crecente, 2012). As a planning tool, the CA model can support "what if" experiments by simulating and evaluating various scenarios based on different development policies. A large number of studies have argued that scenario-based analysis could contribute to the assessment of the potential impacts of urban expansion under various development policies (Mikovits, Rauch, \& Kleidorfer, 2018; Jiang, Deng, Tang, Lei, \& Chen, 2017). In addition to the magnitude analysis of the spatial metrics at the regional scale, the spatiotemporally varying spatial metrics were further revealed under each scenario. Comparing the results of the global comparison can offer a deep insight into the differences among the three scenarios as well as the development characteristics. The examination of future urban expansion scenarios could provide support for developing sustainable urban development policies.

\subsection{Spatiotemporal dynamics of urban expansion}

This study analyzed the spatiotemporal dynamics of the urban expansion during the rapid urbanization process in Hangzhou City, China. The results indicated that the city experienced rapid urban expansion. Hangzhou City represents of a typical urbanization process that is taking place in economic-developed regions. The findings confirmed a general urban expansion trend in the rapid urbanization region (Kukkonen, Muhammad, Käyhkö, \& Luoto, 2018; Estoque \& Murayama, 2013). Urban expansion in developed countries is widely characterized by a low-density, leapfrog land use pattern of residential areas (He, Zeng, Xie, Tan, \& Wu, 2019). While urban expansion in large Chinese cities features a low-density industrial development zones and college towns, as well as unplanned semi-urbanized village communities (Lu, 2007; Heikkila $\& \mathrm{Xu}, 2013)$. Similar to many other cities and areas in China (Luo, Zhang, Wang, \& Gan, 2016; Luo, Xu, Huang, 
Ren, \& Bu, 2018), urban expansion of Hangzhou was the results of multiple factors, for example the accessiblity, population, and policy. China experienced governmentdominated urbanization, which differs from the marketdriven urbanization of developed countries, and resulted in uncontrolled spatial expansion due to oversized urban space in planning for improved political performance (Jin et al., 2017). Moreover, urban sprawl in Chinese cities may have been affected by the non-effective implementations of the related policies, such as crop land protection, urban planning controls, population growth constraints, and land market regulations (Bai, Chen, \& Shi, 2012). It was observed that the urban spatial pattern became more dispersed and fragmented. There was a rapid decrease in the proportion of new developed built-up land with increasing distance from the city core, which has been confirmed by previous studies (Yang et al.. 2018; Pozoukidou \& Ntriankos, 2017), indicating high land use pressure for built-up land in the suburb area. The findings may be due to the fact that the development of transportation system and infrastructure provided a good opportunity for large scale construction around the city center such as industry parks. Like other areas in developing countries, such as Dhaka Metropolitan of Bangladesh and Hanoi, rapid industrialization and urbanization resulted in the rising demand for built-up land, thus much farmland has been converted into built-up land, and the extent of the main city continued to increase along the monocentric development trend (Pham, Yamaguchi, \& Bui, 2011; Zinia \& McShane, 2018). In addition, this trend will continue in the future if there is no major policy change. Under the BAU scenario, Hangzhou City will face significant stress in terms of its land resources and environmental protection by 2030 . As a result, the conflict between limited land resource nearby the city center and rapid urban sprawl will become more apparent, which is consistent with the widely acknowledged conflict between rapid development and limited land resource in developing countries. An imbalance in regional development will exist in rural and peri-urban areas. Jenks, Burton, and Williams (1996) argued that there is a link between the sustainable development and urban land patterns. The compact pattern has been widely acknowledged as a sustainable development pattern with environmental and social advantages (Schneider \& Woodcock, 2008). However, the concentric compact development pattern could cause some problems, such as an imbalance in regional development, congestion and a lack of open space in urban land (Catalán, Saurí, \& Serra, 2008). The scenario-based analysis suggests that the polycentric compact under the $\mathrm{CD}$ scenario could reduce the negative effects of the concentric compact pattern.

Therefore, some related measurements and policies should be implemented to facilitate connectivity between urban fragments and to form polycentric compact development. Furthermore, the spatial metric analysis at the local scale showed that the spatial pattern varied spatially, which can provide a deep insight into the regional differences in urban patterns. The regional differences in urban development patterns should be considered to improve the effectiveness of urban planning policies.

\subsection{Outlook}

Although some valuable results were obtained to offer insights into the spatiotemporal dynamics of urban expansion, challenges lie ahead. Urban expansion can be significantly affected by political and cultural factors (Arsanjani, Helbich, Kainz, \& Boloorani, 2013), which are missing in this model due to their non-spatial characteristics. These factors on this development will also be important, especially when the urban areas of Hangzhou City extend further outward from existing urban areas. To capture more realistic simulation results, it is necessary to incorporate more potential variables into the CA model. In addition, this study selected only a set of spatial metrics to quantitatively characterize the spatial pattern under each scenario. By considering the socioeconomic effects of urban expansion, it would be interesting to adopt additional indicators to better understand the urban expansion characteristics under each scenario.

\section{Conclusions}

This study proposed the integration of remote sensing, spatial metrics and the CA model. The findings of this study are summarized as follows: (1) Hangzhou experienced significant urban expansion during the period of 2002-2013. The urban land increased by $698.59 \mathrm{~km}^{2}$, with an annual growth rate of $63.51 \mathrm{~km}^{2} \mathrm{yr}^{-1}$. The crop land and forest land were the major land resources contributing to the newly developed built-up land. The gradient analysis indicates that the intensity of urban expansion decreased as the distance to the city center increased. (2) As indicated by the spatial metrics, the spatial pattern of the urban land of Hangzhou City has become increasingly dispersed and fragmented. Furthermore, the significant increase in the NP value and the LPI suggests the continuous development of the city core as well as the development of new urban patches. (3) The CA model was developed and calibrated to simulate three different future urban expansion scenarios based on different urban development strategies. Although the total urban land area remained the same, various urban patterns were observed. Urban expansion will continue through both in-filling in the existing urban patches and outward expansion in the future. If the urban expansion continues as presented in the BAU scenario, the peri-urban and rural areas will face significant pressure on their land resources, especially in the environmental protection areas, by 2030 . The rapid urban development around the city core will form a dispersed concentric city. The imbalance in regional development among the city core, peri-urban, and rural areas will deepen. Compared with the two other scenarios, the CD scenario is regarded as the optimized development direction in this study. The development strategy in the CD scenario will allocate the 
newly built-up land in a more economically and environmentally efficient way. In addition, regional coordinated development will be promoted in the $\mathrm{CD}$ scenario by shaping several new development hotspots in the periurban and rural areas.

\section{Acknowledgements}

This work was supported by the $<$ National Natural Science Foundation of China > under Grant [41801197]; <the Key Research and Development Program of Shanxi Province> under Grant [201803D31224]; and <Shanxi Provincial Key Lab of Resources> under Grant [201805D111014].

\section{References}

Abo-El-Wafa, H., Yeshitela, K., \& Pauleit, S. (2018). The use of urban spatial scenario design model as a strategic planning tool for Addis Ababa. Landscape and Urban Planning, 180, 308-318. https://doi.org/10.1016/j.landurbplan.2017.08.004

Aburas, M. M., Ho, M. Y., Ramli, M. F., \& Ash'aari, Z. H. (2016). The simulation and prediction of spatio-temporal urban growth trends using cellular automata models: A review. International Journal of Applied Earth Observation and Geoinformation, 52, 380-389. https://doi.org/10.1016/j.jag.2016.07.007

Agyemang, F. S. K., \& Silva, E. (2019). Simulating the urban growth of a predominantly informal Ghanaian city-region with a cellular automata model: Implications for urban planning and policy. Applied Geography, 105, 15-24.

https://doi.org/10.1016/j.apgeog.2019.02.011

Aladejana, O. O., Salami, A. T., Adetoro, O.-I. O. (2018). Hydrological responses to land degradation in the Northwest Benin Owena River Basin, Nigeria. Journal of Environmental Management, 225, 300-312.

https://doi.org/10.1016/j.jenvman.2018.07.095

Arsanjani, J. J., Helbich, M., Kainz, W., \& Boloorani, A. D. (2013). Integration of logistic regression, Markov chain and cellular automata models to simulate urban expansion. International Journal of Applied Earth Observation and Geoinformation, 21, 265-275. https://doi.org/10.1016/j.jag.2011.12.014

Bai, X., Chen, J., \& Shi, P. (2012). Landscape urbanization and economic growth in China: Positive feedbacks and sustainability dilemmas. Environmental Science \& Technology, 46, 132-139. https://doi.org/10.1021/es202329f

Benza, M., Weeks, J. R., Stow, D. A., López-Carr, D., \& Clarke, K. C. (2016). A pattern-based definition of urban context using remote sensing and GIS. Remote Sensing of Environment, 183, 250-264. https://doi.org/10.1016/j.rse.2016.06.011

Carter, J. G. (2018). Urban climate change adaptation: Exploring the implications of future land cover scenarios. Cities, 77, 7380. https://doi.org/10.1016/j.cities.2018.01.014

Catalán, B., Saurí, D., \& Serra, P. (2008). Urban sprawl in the Mediterranean? Patterns of growth and change in the Barcelona Metropolitan Region 1993-2000. Landscape and Urban Planning, 85, 174-184.

https://doi.org/10.1016/j.landurbplan.2007.11.004

Chakraborti, S., Das, D. N., Mondal, B., Shafizadeh-Moghadam, H., \& Feng, Y. (2018). A neural network and landscape metrics to propose a flexible urban growth boundary: A case study. Ecological Indicators, 93, 952-965.

https://doi.org/10.1016/j.ecolind.2018.05.036

Dadashpoor, H., Azizi, P., \& Moghadasi, M. (2019). Land use change, urbanization, and change in landscape pattern in a metropolitan area. Science of The Total Environment, 655, 707719. https://doi.org/10.1016/j.scitotenv.2018.11.267

Estoque, R.C., \& Murayama, Y. (2013). Landscape pattern and ecosystem service value changes: Implications for environmental sustainability planning for the rapidly urbanizing summer capital of the Philippines. Landscape and Urban Planning, 116, 60-72.

https://doi.org/10.1016/j.landurbplan.2013.04.008

Fuglsang, M., Münier, B., \& Hansen, H. S. (2013). Modelling land-use effects of future urbanization using cellular automata: An Eastern Danish case. Environmental Modelling \& Software, 50, 1-11. https://doi.org/10.1016/j.envsoft.2013.08.003

García, A. M., Santé, I., Boullón, M., \& Crecente, R. (2012). A comparative analysis of cellular automata models for simulation of small urban areas in Galicia, NW Spain. Computers, Environment and Urban Systems, 36, 291-301. https://doi.org/10.1016/j.compenvurbsys.2012.01.001

García-Nieto, A. P., Geijzendorffer, I. R., Baró, F., Roche, P. K., Bondeau, A., \& Cramer, W. (2018). Impacts of urbanization around Mediterranean cities: Changes in ecosystem service supply. Ecological Indicators, 91, 589-606.

https://doi.org/10.1016/j.ecolind.2018.03.082

Hayek, U. W., Efthymiou, D., Farooq, B., von Wirth, T., Teich, M., Neuenschwander, N., \& Grêt-Regamey, A. (2015). Quality of urban patterns: Spatially explicit evidence for multiple scales. Landscape and Urban Planning, 142, 47-62. https://doi.org/10.1016/j.landurbplan.2015.05.010

He, C., Li, J., Zhang, X., Liu, Z., \& Zhang, D. (2017). Will rapid urban expansion in the drylands of northern China continue: A scenario analysis based on the Land Use Scenario Dynamics-urban model and the Shared Socioeconomic Pathways. Journal of Cleaner Production, 165, 57-69. https://doi.org/10.1016/j.jclepro.2017.07.018

He, Q., Zeng, C., Xie, P., Tan, S., \& Wu, J. (2019). Comparison of urban growth patterns and changes between three urban agglomerations in China and three metropolises in the USA from 1995 to 2015. Sustainable Cities and Society, 50, 101649. https://doi.org/10.1016/j.scs.2019.101649

Heikkila, E., \& Xu, Y. (2014). Seven prototypical Chinese Cities. Urban Studies, 51, 827-847.

https://doi.org/10.1177/0042098013492231

Herold, M., Couclelis, H., \& Clarke, K. C. (2005). The role of spatial metrics in the analysis and modeling of urban land use change. Computers, Environment and Urban Systems, 29, 369399. https://doi.org/10.1016/j.compenvurbsys.2003.12.001

Jenks, M., Burton, E., \& Williams, K. (1996). The compact city: a sustainable urban form? London: E\&F Spon.

Jiang, W., Deng, Y., Tang, Z., Lei, X., \& Chen, Z. (2017). Modelling the potential impacts of urban ecosystem changes on carbon storage under different scenarios by linking the CLUE-S and the InVEST models. Ecological Modelling, 345, 30-40. https://doi.org/10.1016/j.ecolmodel.2016.12.002

Jin, X., Long, Y., Sun, W., Lu, Y., Yang, X., \& Tang, J. (2017). Evaluating cities' vitality and identifying ghost cities in China with emerging geographical data. Cities, 63, 98-109. https://doi.org/10.1016/j.cities.2017.01.002

Kaza, N. (2013). The changing urban landscape of the continental United States. Landscape and Urban Planning, 110, 74-86. https://doi.org/10.1016/j.landurbplan.2012.10.015

Kim, H., Kim, Y. K., Song, S. K., \& Lee, H. W. (2016). Impact of future urban growth on regional climate changes in the Seoul Metropolitan Area, Korea. Science of The Total Environment, 571, 355-363. https://doi.org/10.1016/j.scitotenv.2016.05.046 
Kukkonen, M. O., Muhammad, M. J., Käyhkö, N., \& Luoto, M. (2018). Urban expansion in Zanzibar City, Tanzania: Analyzing quantity, spatial patterns and effects of alternative planning approaches. Land Use Policy, 71, 554-565. https://doi.org/10.1016/j.landusepol.2017.11.007

Li, C., Zhao, J., \& Xu, Y. (2017). Examining spatiotemporally varying effects of urban expansion and the underlying driving factors. Sustainable Cities and Society, 28, 307-320. https://doi.org/10.1016/j.scs.2016.10.005

Li, G., Sun, S., \& Fang, C. (2018). The varying driving forces of urban expansion in China: Insights from a spatial-temporal analysis. Landscape and Urban Planning, 174, 63-77. https://doi.org/10.1016/j.landurbplan.2018.03.004

Liu, T., \& Yang, X. (2015). Monitoring land changes in an urban area using satellite imagery, GIS and landscape metrics. Applied Geography, 56, 42-54.

https://doi.org/10.1016/j.apgeog.2014.10.002

Lu, D. (2007). Urbanization process and spatial sprawl in China. Urban Planning Forum, 4, 47-52.

https://doi.org/10.3969/j.issn.1000-3363.2007.04.006

Luo, T., Zhang, T., Wang, Z., \& Gan, Y. (2016). Driving forces of landscape fragmentation due to urban transportation networks: Lessons from Fujian, China. Journal of Urban Planning and Development, 142, 04015013.

https://doi.org/10.1061/(ASCE)UP.1943-5444.0000292

Luo, T., Xu, M., Huang, T., Ren, X., \& Bu, X. (2018). Rethinking the intensified disparity in urbanization trajectory of a Chinese coastal province and its implications. Journal of Cleaner Production, 195, 1523-1532.

https://doi.org/10.1016/j.jclepro.2017.10.083

McGarigal, K., Cushman, S. A., \& Ene, E. (2012). FRAGSTATS v4: Spatial pattern analysis program for categorical and continuous maps. Retrieved from http://www.umass.edu/landeco/ research/fragstats/fragstats.html

Mikovits, C., Rauch, W., \& Kleidorfer, M. (2018). Importance of scenario analysis in urban development for urban water infrastructure planning and management. Computers, Environment and Urban Systems, 68, 9-16.

https://doi.org/10.1016/j.compenvurbsys.2017.09.006

Newland, C. P., Maier, H. R., Zecchin, A. C., Newman, J. P., \& van Delden, H. (2018). Multi-objective optimisation framework for calibration of Cellular Automata land-use models. Environmental Modelling \& Software, 100, 175-200.

https://doi.org/10.1016/j.envsoft.2017.11.012

Pham, H. M., Yamaguchi, Y., \& Bui, T. Q. (2011). A case study on the relation between city planning and urban growth using remote sensing and spatial metric. Landscape and Urban Planning, 100, 223-230.

https://doi.org/10.1016/j.landurbplan.2010.12.009

Pontius, R. G., Boersma, W., Castella, J. C., Clarke, K., de Nijs, T., Dietzel, C., Duan, Z., Fotsing, E., Goldstein, N., Kok, K., Koomen, E., Lippitt, C. D., McConnell, W., Sood, A. M., Pijanowski, B., Pithadia, S., Sweeney, S., Trung, T. N., Veldkamp, A. T., \& Verburg, P. H. (2008). Comparing the input, output, and validation maps for several models of land change. Annals of Regional Science, 42, 11-37. https://doi.org/10.1007/s00168-007-0138-2

Pozoukidou, G., \& Ntriankos, I. (2017). Measuring and assessing urban sprawl: A proposed indicator system for the city of Thessaloniki, Greece. Remote Sensing Applications: Society and Environment, 8, 30-40.

https://doi.org/10.1016/j.rsase.2017.07.005

Santé, I., Marcía, A. M., Miranda, D., \& Crecente, R. (2010). Cellular automata models for the simulation of real-world urban processes: A review and analysis. Landscape and Urban Planning, 96, 108-122.

https://doi.org/10.1016/j.landurbplan.2010.03.001

Schneider, A., \& Woodcock, C. E. (2008). Compact, dispersed, fragmented, extensive? A comparison of urban growth in twenty-five global cities using remotely sensed data, pattern metrics and census information. Urban Studies, 45, 659-692. https://doi.org/10.1177/0042098007087340

Simwanda, M., \& Murayama, Y. (2018). Spatiotemporal patterns of urban land use change in the rapidly growing city of Lusaka, Zambia: Implications for sustainable urban development. Sustainable Cities and Society, 39, 262-274. https://doi.org/10.1016/j.scs.2018.01.039

Son, N. T., Chen, C. F., Chen, C. R., Thanh, B. X., \& Vuong, T. H. (2017). Assessment of urbanization and urban heat islands in Ho Chi Minh City, Vietnam using Landsat data. Sustainable Cities and Society, 30, 150-161. https://doi.org/10.1016/j.scs.2017.01.009

Song, W., Pijanowski, B. C., \& Tayyebi, A. (2015). Urban expansion and its consumption of high-quality farmland in Beijing, China. Ecological Indicators, 54, 60-70. https://doi.org/10.1016/j.ecolind.2015.02.015

Tian, G. J., Ouyang, Y., Quan, Q., \& Wu, J. (2011). Simulating spatiotemporal dynamics of urbanization with multi-agent systems-A case study of the Phoenix metropolitan region, USA. Ecological Modelling, 222, 1129-1138.

https://doi.org/10.1016/j.ecolmodel.2010.12.018

Tian, L., Li, Y., Yan, Y., \& Wang, B. (2017). Measuring urban sprawl and exploring the role planning plays: A Shanghai case study. Land Use Policy, 67, 426-435.

https://doi.org/10.1016/j.landusepol.2017.06.002

Tripathy, P., \& Kumar, A. (2019). Monitoring and modelling spatio-temporal urban growth of Delhi using Cellular Automata and geoinformatics. Cities, 90, 52-63.

https://doi.org/10.1016/j.cities.2019.01.021

United Nations. (2018). World Urbanization Prospects: the 2018 Revision. Retrieved from https://esa.un.org/unpd/wup/

Vanderhaegen, S., \& Canters, F. (2017). Mapping urban form and function at city block level using spatial metrics. Landscape and Urban Planning, 167, 399-409.

https://doi.org/10.1016/j.landurbplan.2017.05.023

White, R., \& Engelen, G. (2000). High-resolution integrated modelling of the spatial dynamics of urban and regional systems. Computers, Environment and Urban Systems, 24, 383400. https://doi.org/10.1016/S0198-9715(00)00012-0

Wu, J., Jenerette, G. D., Buyantuyev, A., \& Redman, C. L. (2011). Quantifying spatiotemporal patterns of urbanization: The case of the two fastest growing metropolitan regions in the United States. Ecological Complexity, 8, 1-8.

https://doi.org/10.1016/j.ecocom.2010.03.002

$\mathrm{Xu}$, C., Haase, D., \& Pauleit, S. (2018). The impact of different urban dynamics on green space availability: A multiple scenario modeling approach for the region of Munich, Germany. Ecological Indicators, 93, 1-12.

https://doi.org/10.1016/j.ecolind.2018.04.058

Xu, Q., Zheng, X., \& Zheng, M. (2019). Do urban planning policies meet sustainable urbanization goals? A scenario-based study in Beijing, China. Science of The Total Environment, 670, 498-507. https://doi.org/10.1016/j.scitotenv.2019.03.128

Yang, Y., Liu, Y., Li, Y., \& Du, G. (2018). Quantifying spatiotemporal patterns of urban expansion in Beijing during 1985-2013 with rural-urban development transformation. Land Use Policy, 74, 220-230.

https://doi.org/10.1016/j.landusepol.2017.07.004 
Zang, Z., Zou, X., Zuo, P., Song, Q., Wang, C., \& Wang, J. (2017). Impact of landscape patterns on ecological vulnerability and ecosystem service values: An empirical analysis of Yancheng Nature Reserve in China. Ecological Indicators, 72, 142-152. https://doi.org/10.1016/j.ecolind.2016.08.019

Zhang, D., Huang, Q., He, C., Dan, Y., \& Liu, Z. (2019). Planning urban landscape to maintain key ecosystem services in a rapidly urbanizing area: A scenario analysis in the Beijing-Tianjin-Hebei urban agglomeration, China. Ecological Indicators, 96, 559-571. https://doi.org/10.1016/j.ecolind.2018.09.030

Zinia, N. J., \& McShane, P. (2018). Ecosystem services management: An evaluation of green adaptations for urban development in Dhaka, Bangladesh. Landscape and Urban Planning, 173, 23-32. https://doi.org/10.1016/j.landurbplan.2018.01.008 